\title{
ENTRE A PSICOLOGIA E A PEDAGOGIA: REFLEXÕES SOBRE O DESENVOLVIMENTO INFANTIL E O CONHECIMENTO ESCOLAR À LUZ DA TEORIA HISTÓRICO-CULTURAL
}

\author{
Eliza Maria BARBOSA ${ }^{1}$ \\ Janaina Cassiano SILVA ${ }^{2}$
}

RESUMO: Analisamos neste trabalho, os aspectos que marcam a relação da Pedagogia com a Psicologia da Educação, sobretudo a relação entre desenvolvimento e aprendizagem humana explicitada pela teoria Psicogenética. Realizamos uma análise crítica dessa relação à luz das contribuições da Teoria Histórico-Cultural. Demonstramos que a partir da alguns preceitos, a teoria psicogenética estabelece um modelo de educação que toma o desenvolvimento dos processos cognitivos como conteúdo básico para as ações educativas, considerando-se que o êxito na transmissão de conhecimentos às crianças depende prioritariamente da existência de esquemas de assimilação inerentes à atividade do sujeito. Entretanto, pautados na Teoria HistóricoCultural, reafirmamos uma compreensão da criança como sujeito que tem necessidade de aprender e crescer em um mundo de objetos, pessoas e lugares portadores de saberes. Assim deve ser pensada a ampliação do conhecimento cultural e humano produzido na escola engendrada pelas ações pedagógicas. Quanto mais conhecimento as crianças dominam, maior o seu poder sobre os processos que determinam suas vidas e suas condições de existência na realidade social. Ou seja, é através da apropriação dos processos engendrados culturalmente (pela educação) que, no decurso da vida as crianças adquirem as propriedades e faculdades verdadeiramente humanas.

PALAVRAS-CHAVE: Psicologia da educação. Psicogenética. Teoria HistóricoCultural. Educação infantil.

\section{INTRODUÇÃO}

Se considerarmos a publicação da Constituição de 1988 (BRASIL, 1988) como um instrumento que deu legitimidade à educação e aos cuidados com as crianças, podemos assim somar aproximadamente 25 anos de fomento de diversos temas pertinentes à Educação Infantil seja no campo acadêmico, das políticas públicas ou ainda, institucionais. De lá para cá, os esforços empreendidos se ramificam na tentativa

\footnotetext{
${ }^{1}$ Professora Assistente do Departamento de Psicologia da Educação. UNESP - Universidade Estadual Paulista Júlio de Mesquita Filho. Faculdade de Ciências e Letras, Campus Araraquara. Araraquara - SP Brasil.14800-901 - eliza@fclar.unesp.br.

${ }^{2}$ Professora Adjunta no Instituto de Biotecnologia- Curso de Psicologia e no Programa de Pós-graduação em Educação - PPGEDUC. UFG - Universidade Federal de Goiás. Catalão - GO - Brasil. 75704-020 janacassianos@gmail.com.
} 
de garantir o direito constitucional das crianças de receber atendimento de qualidade em creches e pré-escolas. Tem se evidenciado esses esforços em diferentes âmbitos, tais como: Organismos internacionais ${ }^{3}$ com destaque para as ações do Fundo das Nações Unidas para a Infância (UNICEF) e do Banco Mundial que financiam projetos sociais e de educação em países em desenvolvimento como o Brasil. Em alguns Ministérios, Secretarias Especiais, Secretarias Municipais e Estaduais de educação, Universidades ou Centros de Pesquisa e nas próprias instituições educativas, as ações orientam-se para produzir impactos significativos nos processos de formação das crianças em seus primeiros anos de vida.

Nesses diferentes âmbitos são eleitos objetivos e diretrizes que dão teor a projetos implantados ou em andamento, visando promover o desenvolvimento psicológico das crianças e sua relação indissociável com as exigências culturais de formação humana. Contudo, acreditamos que há nesses âmbitos, motivações diversas, inclusive ideológicas, bem como valorações divergentes quanto ao papel que as instituições educativas escolares devem exercer.

Referimo-nos à oposição consolidada nos discursos oficiais, em documentos que regulamentam as políticas educacionais, em intensos debates acadêmicos da área da Educação Infantil e nas práticas educativas. Por um lado, uma compreensão de que a função da Educação Infantil é favorecer a concretização das etapas de desenvolvimento psicológico, ou o mesmo que, educar para o desenvolvimento e por outro, uma defesa de que as práticas pedagógicas se ocupem em produzir saberes culturais cientificamente validados com as crianças, traduzindo-se pela perspectiva de educar para o conhecimento.

Tal oposição é reconhecida no documento Introdutório dos Referenciais Curriculares Nacionais para Educação Infantil do Ministério da Educação (BRASIL, 1998) por ocasião de se afirmar a função de cuidar e educar das crianças, indissociavelmente. $\mathrm{O}$ documento admite que haja polêmicas neste entorno.

Polêmicas sobre cuidar e educar, sobre o papel do afeto na relação pedagógica e sobre educar para o desenvolvimento ou para o conhecimento têm constituído portanto, o panorama de fundo sobre o

\footnotetext{
${ }^{3}$ Em outro trabalho apresentamos as restrições aos programas financiados por este órgão por entendermos que há uma manobra política e ideológica incorporada a eles que culmina na substituição de programas formais em programas informais de educação para as crianças, produzindo uma educação para a subalternidade como já denunciado por Rosemberg (2002).
} 
qual se constroem as propostas em educação infantil. (BRASIL, 1998, p.18).

Frente a essa circunstância, o presente artigo tem por objetivo favorecer a compreensão desta oposição que vem caracterizando as práticas educativas escolares na Educação Infantil. Para tanto, nos apoiamos na história recente de influência da Psicologia do Desenvolvimento sobre a Pedagogia, sobretudo nos processos de desenvolvimento e aprendizagem dos escolares menores de seis anos. Pretendemos reafirmar em nossas conclusões uma compreensão da criança como sujeito que tem necessidade de aprender e crescer em um mundo de objetos, pessoas e lugares portadores de saberes. Este princípio, expressa-se no campo da Psicologia, na perspectiva Histórico-Cultural dos teóricos da chamada Escola de Vygotsky.

Tal perspectiva anuncia uma ampla interdependência dos processos de desenvolvimento psicológico com a cultura em geral, especificamente as que se concretizam em instituições educativas infantis. Pautados em alguns princípios da Teoria Histórico-Cultural de Vigotskii $^{4}$ (2006) e Leontiev (1978) concebemos a aprendizagem como um processo apoiado na cultura e, a criança como um sujeito que se depara no mundo cultural com a necessidade de aprender, com diferentes formas de saber e sua atividade neste mundo possui uma dinâmica que pressupõe meios de ação e recursos que não somente aqueles já desenvolvidos nas crianças.

Esta constatação deveria fragilizar a tese de que as etapas de desenvolvimento se consolidam somente pela ação das próprias crianças em contato direto com a realidade e objetos presentes nas situações de aprendizagem, engendradas em sua maioria, por forças circunstanciais ou ocasionais. Por outro lado, nos parece legítimo e adequado que as práticas educativas na Educação Infantil se ocupem do processo de consolidação do desenvolvimento intelectual das crianças caso entenda-se, que este processo torna-se possível, somente por proposições educativas formalmente desenvolvidas nas préescolas e pela via dos conhecimentos desenvolvidos com aquelas. Tais proposições produzem algo fundamentalmente novo no desenvolvimento das crianças.

Chegamos assim a uma exigência. Compreender a evolução teórica, no campo da Psicologia do paradigma que concebe o desenvolvimento numa perspectiva evolutiva e maturacional (WARDE, 2003) limitando as relações de produção de saberes pelas

\footnotetext{
${ }^{4}$ Adotaremos ao nos reportarmos a este autor a grafia Vigotski, porém nas citações diretas e indiretas manteremos a grafia utilizada em cada edição. Duarte (2004) destacou que devido ao fato do idioma russo ter um alfabeto diferente do nosso, têm sido utilizadas diferentes formas de escrever o nome desse autor.
} 
crianças àquilo que elas já realizam de forma efetiva. Esta perspectiva figura um dos eixos da oposição inicialmente anunciada e se transmuta no equívoco que leva os professores a negligenciar o acesso das crianças aos saberes culturais produzidos historicamente, contribuindo para que se caracterize uma nova roupagem para a marginalização das crianças de países como o Brasil, cuja história do desenvolvimento econômico e social muito ficou devendo-lhes em termos de garantia e acesso aos seus direitos mais básicos como saúde, educação e cultura.

A trajetória descrita a seguir apoiada em Warde (2003) e Carvalho (2002), demonstra a consolidação de uma perspectiva psicológica orientadora de práticas educativas que preveem a consolidação das etapas do desenvolvimento psicológico como meta fundamental para a educação, subordinando o processo de construção dos saberes culturais pelas crianças àquela consolidação.

Resta-nos dizer que, se o desenvolvimento humano consiste na construção de uma série de estruturas que determinam a amplitude e natureza das relações dos indivíduos com seu meio sociocultural, então um dos objetivos da educação escolar deve ser o favorecimento daquele (COLL; MARTÍ, 1996). Porém, cientes de que todo tipo de educação é essencialmente uma prática social, sua função primordial é assim a transmissão dos saberes historicamente construídos e culturalmente organizados, despertados em sua maioria, pela aprendizagem escolar.

Deste modo, subdividimos esse artigo em três partes. Na primeira faremos um breve histórico da influência da psicologia nas práticas educativas, especificamente na faixa etária de zero a seis anos, com enfoque nos princípios teóricos de Jean Piaget. Posteriormente, traremos as contribuições da perspectiva Histórico-Cultural para pensarmos a relação entre desenvolvimento e aprendizagem, além das práticas pedagógicas com crianças pequenas. Por fim, nas considerações finais, realizaremos reflexões a partir das discussões empreendidas no decorrer desse artigo.

\section{A psicologia e a educação: tramas e diálogos sobre o desenvolvimento das crianças}

A compreensão do movimento histórico que coloca em foco a criança como objeto e destinatária dos estudos pedagógicos e psicológicos, durante todo o século passado parece-nos imprescindível para cumprir o objetivo de nossa discussão. Neste sentido, Carvalho (2002, p.1) afirma que o século XX tem como cenário o ingresso de 
uma grande massa de crianças nas escolas da sociedade industrializada e isso implicou na necessidade "[...] imperiosa de estudo e compreensão do desenvolvimento infantil". Tal fato justifica em boa parte, a forte influência da Psicologia na construção do ideário pedagógico. Com o objetivo de demonstrar essa influência, a autora produz uma análise de temáticas específicas e fundamentais que expressam as discussões da área educacional ao longo do século XX, presentes ainda hoje.

Destaca-se entre tais temáticas a relação entre desenvolvimento e aprendizagem, a importância da educação para o desenvolvimento do psiquismo e o papel do professor no processo ensino-aprendizagem, examinando-as à luz do pensamento de Dewey, Claparède, Piaget, Wallon e Vigostski, identificando a partir deste exame duas posições entre as quais eles se situam. A primeira posição, constituída pelos três primeiros autores, sugere uma subordinação do processo educativo ao desenvolvimento das estruturas cognitivas da criança. Por sua vez, as ideias dos dois últimos, anunciam um papel específico para a escola, quer seja, o ensino de conteúdos científicos e socialmente relevantes, permitindo às crianças o domínio de conhecimentos formais. Concomitante a esta defesa explicita-se a aprendizagem como um dos principais motores para o desenvolvimento.

Em percurso semelhante Warde (2003) realiza uma discussão que ao explicitar os meandros da relação entre a Psicologia e a Pedagogia durante os dois últimos séculos (XIX e XX), nos permite compreender como a continuidade da defesa empreendida por autores como Dewey, Claparède e James em seu tempo e, extensiva a autores contemporâneos como Piaget, por exemplo, reforçou a tese da psicologia como ciência de referência da Pedagogia e por essa razão instrumento de luta, segundo Claparède (1940 apud WARDE, 2003, p.324) “[...] contra uma filosofia especulativa e metafísica, bem como de luta contra a inoperância e despreparo dos poderes instituídos em questões educacionais".

As primeiras décadas do século XX protagonizaram um período de grande desenvolvimento das teses psicológicas sob as práticas educativas escolares. Warde (2003, p.328) afirma que a Psicologia Funcional cujas ideias evolucionistas são atribuídas a James, Dewey e Claparède produziram um forte impacto sobre os primeiros psicólogos da criança, europeus e norte-americanos, favorecendo para que passassem de “[...] uma filosofia especulativa para uma psicologia científica, ou a subordinação da doutrina filosófica às descobertas científicas". 
A leitura de Warde (2003) sobre as proposições psicológicas como mediadoras das práticas pedagógicas e do interesse pela infância apoia-se em uma análise da sucessão de pensadores do século XX. Sua leitura revela que a grande expectativa depositada sobre os estudos psicológicos desdobrava-se em dois objetivos: uma defesa pragmática de que a Psicologia Experimental deveria fornecer as bases para uma Pedagogia científica apartada do "[...] irracionalismo das filosofias essencialistas e fundamentalistas" (WARDE, 2003, p.324) e a compreensão de que as relações entre a Psicologia e a Filosofia, posteriormente entre a Psicologia e a Pedagogia, modificam-se na medida em que os problemas de ensino-aprendizagem e desenvolvimento humano obrigam a psicologia a prestar atenção na criança, que em número cada vez maior entra para a escola.

$\mathrm{Na}$ defesa de ambos os objetivos caracterizam-se distintas perspectivas para a relação entre a Psicologia e a Pedagogia. Os teóricos pragmáticos tendem a entender esta segunda, como campo de aplicação da primeira, portanto a educação deve estar atenta ao aspecto ativo da aprendizagem da criança que se põe em movimento pelo contato com seu ambiente, não devendo, portanto ser considerada simplesmente o resultado da instrução, mas uma reorganização da experiência que esclarece e aumenta o sentido desta. Esta reorganização aumentaria à aptidão dos indivíduos em dirigir o curso das experiências subsequentes (CARVALHO, 2002).

Noutra posição, encontram-se os teóricos que acreditam que a Psicologia tem algo a dizer sobre a organização do campo pedagógico, defendendo a escola como um campo de estudo de particular importância, se a considerarmos uma instituição socialmente determinada por diversos fatores que também afetam o grupo de crianças que ela reúne, sendo que qualquer perspectiva psicológica que aborde somente o indivíduo não será capaz de resolver problemas inerentes à educação escolar (CARVALHO, 2002).

Seguindo a discussão de Carvalho (2002) sobre a história das ideias psicológicas, a autora indica que as necessidades práticas da escolarização das crianças a partir do século XX, produziram entre outras coisas a urgência em se pensar temas relativos ao que na Filosofia eram tratados por conhecimento, mas que na Psicologia se reapresentam como desenvolvimento e aprendizagem. Nas palavras de Warde (2003, p.328), “[...] não se trata mais de perguntar sobre as condições e possibilidade de conhecimento, mas sim sobre as condições e possibilidade de aquisição dos conhecimentos já produzidos”. Na tentativa de responder a essa questão entendemos 
que se revitaliza nos dias atuais uma perspectiva psicológica de orientação pragmática que subordina a aprendizagem ao processo de amadurecimento das estruturas endógenas viabilizadas pelo desenvolvimento, com profundas implicações no processo de ensino escolar.

Carvalho (2002) afirma que das duas posições por ela examinada há o predomínio daquela representada pelos estudos de Claparède, Dewey e mais recentemente Piaget, o qual nos deteremos neste artigo. A autora ressalta que os ideais destes teóricos contribuíram para a consolidação de uma hegemônica concepção educativa que considera o próprio pensamento como o conteúdo básico a ser desenvolvido pela educação, devendo o professor, "[...] compreender e acompanhar a criança nas etapas de construção da inteligência, reorganizando didaticamente o material, de modo a torná-lo assimilável, de acordo com o estágio do desenvolvimento em que ela se encontra". (CARVALHO, 2002, p.10).

Examinando as principais ideias dos autores acima, Carvalho (2002) indica que a necessidade de explicar cientificamente o processo de aquisição de conhecimento já preocupava cientistas como Herbart (1776-1841) ainda no século XIX. A autora pontua que Herbart havia empreendido um grande esforço em explicar o funcionamento mental chegando a afirmar que a consciência era o núcleo da vida mental formada por representações do real, tendo se constituído, portanto, num dos mais expressivos críticos da teoria das faculdades mentais clássicas que postulava a existência de faculdades mentais inatas.

Sob a influência dos pressupostos de Herbart, Dewey (1959 apud CARVALHO, 2002, p.3) afirma que o legado daquele autor para as questões relativas ao ensino foi substancial por afirmar que este último deveria ser considerado uma "[...] atividade consciente, intencional, com método e processo definidos”. Entretanto, Dewey localiza nos princípios de Herbart o que ele considerou uma omissão: o aspecto ativo da aprendizagem das crianças, perspectiva que se tornou fundamental para as demais ideias desenvolvidas por Dewey e que localizamos também na defesa da epistemologia psicogenética (DEWEY, 1959 apud CARVALHO, 2002).

Baseada na análise do pensamento de Dewey, Carvalho (2002) destaca que se estabelece um princípio também equacionador de um conjunto de ideias que entendem a criança como um ser vivo, com funções ativas em contínuo processo de interação com o meio, que necessita se adaptar às condições oferecidas e, a escola, ou melhor, o processo de ensino cumpriria o papel de selecionar as experiências úteis realizadas pela 
humanidade para ser vividas pelas crianças. Destes princípios, extraímos a evidência de uma relação determinante entre experiência ativa e necessidade de adaptação, compreensão que também localizamos no pensamento de Claparède (1940 apud CARVALHO, 2002) ao afirmar que a inteligência é um instrumento de adaptação acionado quando outros mecanismos como o hábito ou o instinto falham.

Em Claparède encontramos a primeira tentativa de diferenciação de inteligência e pensamento, indicando uma pertinência entre o pensamento e a teoria do conhecimento, razão pela qual o autor indica que a escola deveria ensinar para desenvolver as características da inteligência, subordinando como se pode perceber, o ensino e o saber ao desenvolvimento da inteligência.

É neste contexto que se legitimam as valiosas contribuições de Piaget (18961980), estudioso que se dedicou prioritariamente às questões epistemológicas sem, no entanto, ter deixado de contribuir para a reflexão das questões educacionais. Preocupado em responder como o ser humano passa de um menor a um maior conhecimento, Piaget produziu uma teoria construtivista sustentada em alguns princípios descritos anteriormente, entre eles o de que o desenvolvimento da inteligência se dá através do aspecto ativo impulsionador da construção das estruturas cognitivas consolidadas pelo processo de equilibração, que por sua vez corresponde aos processos de regulação e compensação, ocorridos sempre que o indivíduo constrói um conhecimento.

Para a epistemologia construtivista, o desenvolvimento resulta das sucessivas equilibrações que vão constituindo os estágios ordenados e sucessivos do desenvolvimento e apresenta-se como pré-condição para as aprendizagens, ou seja, a criança só aprende aquilo que já pode ser incorporado por suas estruturas cognitivas (CARVALHO, 2002). O desenvolvimento é, portanto um processo auto-regulado de mecanismos funcionais que ocorre segundo uma dinâmica que considera, o objeto exterior (conhecimento) como aquilo que impõe a necessidade/ação do organismo cujo funcionamento se dá segundo as características típicas de cada estágio e que têm seus limites de funcionamento definidos por essas mesmas características. Em outras palavras, o encontro com o conhecimento e sua efetivação depende prioritariamente de um funcionamento que é regido por leis gerais de regulação internas.

Em Piaget (1974), encontramos uma ampla discussão a respeito da relação entre a aprendizagem e o desenvolvimento. O projeto científico empreendido pelo autor e seus colaboradores, buscava responder à hipótese de que as estruturas lógicas pudessem ser aprendidas e ainda, se a lógica seria algo inerente aos mecanismos da aprendizagem. 
Perguntavam-se qual é o papel do sujeito (se é que de fato havia uma atividade do sujeito) e do objeto, no processo de construção das propriedades físicas e lógicomatemática que viabilizam o conhecimento sobre fatos, objetos ou fenômenos.

Para tal feita, Piaget (1974) estabelece como ponto de partida um exame quanto ao alcance epistemológico das teorias de aprendizagem em suas variedades apriorísticas e empiristas que figuravam em seu tempo, afirmando em termos genéricos que suas diferenças, impediam a constituição de uma teoria geral de aprendizagem. Para a análise da proposição empirista, em termos psicogenéticos, era preciso demonstrar o valor de uma leitura da experiência que consista em constatações puras, fornecendo assim um conhecimento por aquisição independente de toda a lógica. Por outro lado, em termos apriorísticos era preciso demonstrar se, do ponto de vista epistemológico, pode-se afirmar que não há aprendizagem das estruturas lógicas e por isso, os conhecimentos resultariam de uma condição à priori. (PIAGET, 1974).

Por analogia a este problema epistemológico que implicava na verificação das leis e interpretações das teses apriorística e empirista, constitui-se outro que buscava compreender se, uma vez admitida a atividade do sujeito no processo de aprendizagem das estruturas lógicas, esta aprendizagem resultaria exclusivamente das aquisições tiradas da experiência física (percepção registrada a partir dos objetos). Deste modo, as aprendizagens das estruturas lógicas seriam redutíveis às das estruturas físicas ou ainda, se as aprendizagens destas primeiras comportariam “[...] uma espécie de círculo (ou espiral) tal que, para aprender a construir uma estrutura lógica é necessário partir de outras estruturas lógicas ou pré-lógicas que se diferenciam por um conjunto de exercícios operatórios ou pré-operatórios até atingirem a nova estrutura". (PIAGET, 1974, p.24).

Admitir a existência daquele movimento circular, presumido das estruturas lógicas aprendidas e das estruturas anteriores sugere, segundo Piaget (1974), uma interpretação interacionista que admite o papel da existência e atividades do sujeito. Neste sentido, os estudos piagetianos que se seguem, demonstram cinco teses fundamentais sendo as duas últimas mais amplamente discutidas neste texto, por entendermos que as mesmas comportam os elementos teóricos necessários à nossa argumentação, quanto à predominância de um modelo de educação para a Infância que se preocupa em consolidar as etapas do desenvolvimento.

A primeira tese admite a existência de uma certa aprendizagem das estruturas lógicas, enquanto a segunda informa que estas aprendizagens permanecem muito limitas 
quando resultam da leitura obtida pela experiência física ou da articulação das intuições pré-operatórias. A terceira tese refere-se à compreensão de que a aprendizagem das estruturas lógicas, ocorridas durante a permanência das crianças nas formas de pensamento pré-operacional (de 5 anos e meio até aproximadamente 7 anos), consistem numa construção de coordenadas novas por diferenciação de coordenadas anteriores, “[...] segundo um processo circular tal que, para aprender uma estrutura lógica é necessário utilizar outras que conduzam a ela ou que a impliquem". (PIAGET, 1974, p.26).

As demais teses são centrais para a compreensão da atividade do sujeito na estruturação e funcionamento do comportamento. Piaget (1974) afirma que a aprendizagem será tanto mais eficaz quando provocar um exercício operatório, ou seja, operações simples exigirão menos as contribuições do sujeito (uso quase exclusivo de organizações hereditárias) enquanto as mais complexas (implicam no estabelecimento de relações, classes, etc.) aumentam a necessidade de ações dos sujeitos para a concretização da aprendizagem. Por compreensão análoga, a quinta tese se explicita pela diferenciação entre a experiência física e lógico-matemática. Piaget (1974) esclarece que embora ambas correspondam a ações do sujeito sobre os objetos, na primeira, as ações produzem-se com o objetivo de revelar as propriedades que ainda são abstratas no objeto, enquanto a segunda revela propriedades que estão abstratas das ações mesmas do sujeito. Por seu efeito, o sujeito chega, a partir de um certo nível de abstração a um ponto em que sua ação sobre o objeto se torna inútil já que, as novas ações coordenadas se configuram simbolicamente e a partir daí o sujeito procede de maneira dedutiva.

Como essas duas últimas teses se articulam e se configuram nas práticas pedagógicas dos professores da Educação Infantil? Por que essas e outras orientações teóricas tornaram-se hegemônicas na condução dos processos educativos escolares da criança pequena?

Sem pretender responder a complexidade das questões que as perguntas acima indicam, nosso propósito é discutir dados reais das práticas educativas que observamos nas instituições educativas infantis que, orientadas por princípios psicogenéticos, especialmente os que reconhecem o papel do sujeito na relação de conhecimento, limitam-se, predominantemente, a acompanhar a passagem de ações coordenadas empiricamente para outras coordenadas simbolicamente como se estas últimas, 
resultassem de um processo natural que prescinde da intencionalidade, necessária ao trabalho escolar.

O que observamos é uma circularidade das ações realizadas pelas crianças, quase sempre de modo individual, já que elas se voltam para as propriedades presentes e reveladas na própria materialidade dos objetos e por isso, já dominadas pelas crianças. Ao relermos as duas últimas teses piagetianas, veremos que há de fato uma proposição do sujeito da aprendizagem como alguém que articula as ações necessárias ao domínio do objeto seja em seu nível empírico ou simbólico, levando um número significativo de professores a limitar-se a identificar as ações que as crianças já desenvolveram de modo autônomo, voltando-se para as crianças exclusivamente como sujeito cognitivo, revelando as estruturas lógicas e empíricas dominadas, porém sem um preocupação com o conteúdo à partir do qual essa estruturas operam. Ou seja, há uma mobilização em torna de classificar as crianças em função das ações e estruturas consolidadas e consequentemente, uma secundarização do conteúdo escolar que é dado como objeto para essas ações.

Esta perspectiva psicológica tornou-se imperativa para a defesa dos métodos ativos e para a disseminação de uma compreensão frequente entre os educadores, de que a melhor educação é aquela que se realiza pelas ações auto-reguladas das crianças de onde derivam todos os saberes culturais. Acreditamos que é do conjunto dessas ideias, bem como a citação a seguir, que um número significativo de educadores e teóricos partem para defender que a função primordial da Educação Infantil é desenvolver o pensamento, não devendo as práticas pedagógicas ocupar-se de atividades de ensino, nem mesmo em promover com as crianças situações formais de aprendizagem. Afirma Piaget (2003, p.34):

Se se deseja, como necessariamente se faz cada vez mais sentir formar indivíduos capazes de criar e de trazer progresso à sociedade do amanhã, é claro que uma educação ativa verdadeira é superior a uma educação consistente apenas em moldar os assuntos do querer já estabelecido e os do saber pelas verdades simplesmente aceitas. Mas caso se tenha por objetivo formar espíritos conformistas prontos a trilhar os caminhos já traçados das verdades adquiridas o problema implica em determinar se a transmissão das verdades estabelecidas terá mais êxito mediante procedimento de simples repetição ou mediante uma assimilação mais ativa. 
De acordo com o exposto, estabelece-se um modelo de educação que toma o desenvolvimento do pensamento infantil como conteúdo básico para as ações educativas. Em tal modelo, considera-se que a aquisição de conhecimentos depende em parte das transmissões educacionais e sociais, porém o êxito de tais transmissões depende prioritariamente da existência de esquemas de assimilação inerentes à atividade do sujeito.

Tal compreensão produz uma implicação visível nos contextos educativos: uma forma de conceber o conhecimento como algo que se concretiza nas estruturas cognitivas dos alunos sempre que o ambiente for adequadamente planejado para favorecer as ações das crianças. A aprendizagem é entendida como um processo exterior, de certa forma, paralelo ao desenvolvimento, mas que não o altera. Neste caso, educar as crianças menores de 6 anos significa exclusivamente assegurar-lhes a consolidação de aspectos de seu desenvolvimento cognitivo.

Carvalho (2002) parte de uma concepção inspirada noutra posição, discutida a seguir, para afirmar que uma educação entendida como fenômeno histórico e cultural tem mais condição de refletir sobre os desafios cotidianos da realidade escolar, pois situa seu objeto e função - ensinar saberes científicos e socialmente relevantes às crianças - na matriz histórica e cultural, que propõe outro modo de conceber as contribuições psicológicas e a educação, por derivação da forma como concebem a relação do indivíduo com o meio social e cultural.

\section{A criança, a educação infantil e a sistematização de conhecimentos e hábitos novos: temas necessários à Pedagogia}

Segundo Carvalho (2002), nas obras de Wallon e Vigotski, os preceitos marxistas ${ }^{5}$ indicam que é através das relações humanas que o ser humano torna-se geneticamente social. Do princípio dialético de que as propriedades típicas das funções intelectuais psicológicas superiores possuem origem no social e de que a cultura vai se integrando à natureza de cada indivíduo, Vigotski (1896-1934) e os demais autores da

\footnotetext{
5 Muitos pesquisadores desvinculam a obra dos teóricos da Escola de Vigotski dos pressupostos marxistas, Duarte (2004) e Lombardi (2010) apresentam algumas hipóteses. Duarte (2004, p.2) afirma que esse movimento ocorre de duas maneiras, a saber: "[...] 1) aproximação entre a teoria vigotskiana e a concepção psicológica e epistemológica interacionista-construtivista de Piaget; 2) interpretação da teoria vigotskiana como uma espécie de relativismo culturalista centrado nas interações linguísticas intersubjetivas". Para Lombardi (2010, p.23) um dos argumentos utilizados pela grande imprensa para desqualificar o marxismo está no fato desta afirmar "[...] que assumir o marxismo é adotar uma perspectiva envelhecida, que não tem mais nada a dizer para o homem globalizado do século XXI".
} 
Escola de Vigotski, produzem uma discussão em torno de questões com grande implicação para a educação como, por exemplo, o desenvolvimento e aprendizagem.

Os autores soviéticos afirmam que o ingresso na escola muda de modo radical a situação da criança na sociedade, transforma fundamentalmente todo seu sistema de relações mútuas com os adultos e com outras crianças. A criança começa uma atividade séria, de significação social. Nesse momento, ela deve assimilar um conjunto determinado de conhecimentos e hábitos e tem que aprender de uma maneira sistemática, quando isto lhe foi exigido. Para Elkonin (1969), a criança começa a apresentar relações sérias com o mestre e com o conjunto de estudantes de sua classe e, em parte com toda a escola. A forma como o escolar realiza suas obrigações determina sua situação na escola, no conjunto da classe, na família e também suas relações mútuas com as demais crianças e adultos. Suas relações concretas com os que lhe rodeiam começam a estar determinadas pelos resultados de sua atividade, pela maneira como cumpre suas obrigações escolares, de membro do conjunto de sua classe e de membro da família.

Acerca da relação entre desenvolvimento e aprendizagem, Vigotskii (2006) apresenta e agrupa as teorias mais importantes em três categorias fundamentais. A primeira implica uma completa independência entre o processo de desenvolvimento e o de aprendizagem e chega até a postular uma nítida separação de ambos os processos no tempo. Nessa categoria, invariavelmente, o curso do desenvolvimento precede o da aprendizagem, ou seja, a aprendizagem segue sempre o desenvolvimento. A segunda categoria afirma, pelo contrário, que a aprendizagem é desenvolvimento, segundo James (apud VIGOTSKII, 2006, p.105), “[...] a educação pode ser definida como a organização de hábitos de comportamento e de inclinações para a ação". Nessa categoria, constatamos que o desenvolvimento vê-se reduzido a uma simples acumulação de reações. Por fim, na terceira percebemos que há uma tentativa de conciliação dos extremos das teorias anteriormente apresentadas, o que supõe uma teoria dualista do desenvolvimento. Desta forma, de um lado, o processo de desenvolvimento está concebido como independente do de aprendizagem, porém, de outro, esta mesma aprendizagem considera-se coincidente com o desenvolvimento.

De acordo com os psicólogos ou os pedagogos puramente teóricos, para Vigotskii (2006, p.107): 
[...] o docente deve pensar e agir na base da teoria de que o espírito é um conjunto de capacidades (capacidade de observação, atenção, memória, raciocínio, etc) e que cada melhoramento de qualquer destas capacidades significa o melhoramento de todas as capacidades em geral.

Os métodos que permitem que a aprendizagem especializada influa sobre o desenvolvimento geral somente funcionam porque há elementos materiais e processos comuns. A esse respeito Vigotskii (2006, p.108) afirma que:

Somos governados pelos hábitos. Daqui resulta que desenvolver o intelecto significa desenvolver muitas capacidades específicas e independentes e formar muitos hábitos específicos, já que a atividade de cada capacidade depende do material sobre o qual essa capacidade opera. $\mathrm{O}$ aperfeiçoamento de uma função ou de uma atividade específica do intelecto influi sobre o desenvolvimento das outras funções e atividades só quando estas têm elementos comuns.

Vigotskii (2006, p.109) destaca que a aprendizagem da criança tem início anteriormente à aprendizagem escolar, ou seja, "[...] toda a aprendizagem da criança na escola tem uma pré-história”. Além disso, enfatiza que, primeiramente, devemos compreender a relação entre aprendizagem e desenvolvimento em geral e, posteriormente, as características específicas desta inter-relação na idade escolar. "É uma comprovação empírica, freqüentemente verificada e indiscutível, que a aprendizagem deve ser coerente com o nível de desenvolvimento da criança". (VIGOTSKII, 2006, p.111).

$\mathrm{O}$ autor afirma que para se definir a efetiva relação entre desenvolvimento e aprendizagem, é necessário determinar, no mínimo, dois níveis de desenvolvimento infantil: o desenvolvimento efetivo e o desenvolvimento potencial da criança. Entendemos o primeiro como “[...] o nível de desenvolvimento das funções psicointelectuais da criança que se conseguiu como resultado de um específico processo de desenvolvimento já realizado.” (VIGOTSKII, 2006, p. 111). Em relação ao segundo temos que “[...] a diferença entre o nível das tarefas realizáveis com o auxílio dos adultos e o nível das tarefas que podem desenvolver-se com uma atividade independente define a área de desenvolvimento potencial da criança.” (VIGOTSKII, 2006, p.112). Vigotskii (2006), também, apresenta que a zona de desenvolvimento potencial da criança permite-nos analisar o processo de desenvolvimento e maturação já produzidos, até o momento, bem como os processos que ainda estão ocorrendo e se desenvolvendo, 
além de determinar os futuros passos e a dinâmica do desenvolvimento infantil. Nesse ponto cabe esclarecermos, segundo Chaiklin (2011), que o principal no que se refere à assistência dada pelo outro mais experiente é o entendimento do significado dessa assistência em relação à aprendizagem e o desenvolvimento da criança, e não à competência em si desta pessoa.

Vigotskii (2006) considera que a aprendizagem não é em si mesma, desenvolvimento, porém, uma correta organização da aprendizagem da criança conduzirá ao desenvolvimento mental, ativará todo um grupo de processos de desenvolvimento, sendo que esta ativação não poderia produzir-se sem a aprendizagem. Por isso, “[...] a aprendizagem é um momento intrinsecamente necessário e universal para que se desenvolvam na criança essas características humanas não-naturais, mas formadas historicamente". (VIGOTSKII, 2006, p.115).

$\mathrm{O}$ autor ressalta que a aprendizagem e o desenvolvimento da criança, ainda que diretamente ligados nunca se produzem de modo simétrico e paralelo. $\mathrm{O}$ desenvolvimento da criança nunca acompanha a aprendizagem escolar, como uma sombra segue o objeto que a projeta. Os testes que comprovam os progressos escolares não podem, portanto, refletir o curso real do desenvolvimento da criança. "Existe uma dependência recíproca, extremamente complexa e dinâmica, entre o processo de desenvolvimento e o da aprendizagem, dependência que não pode ser explicada por uma única fórmula especulativa apriorística”. (VIGOTSKII, 2006, p.116).

Elkonin (1969) acrescenta que considerar as particularidades da idade das crianças não deve consistir em que o pedagogo se oriente somente pelo nível de desenvolvimento já alcançado e típico para esta idade. Isto significaria deter-se artificialmente ao desenvolvimento da criança. A função do pedagogo é fazer adiantar o desenvolvimento psíquico das crianças, formar o novo em seu desenvolvimento psíquico, facilitar o desenvolvimento do novo. O pedagogo não pode partir somente do nível de desenvolvimento existente, este deve orientar-se para as perspectivas do desenvolvimento, sobretudo para as mais próximas, e, regendo-se por estas, dirigir todo o desenvolvimento da criança. Somente ao conhecer bem o que é próprio das crianças de uma idade determinada e o que pode a estas ser acessível (em condições determinadas, no grau seguinte do desenvolvimento, tanto de suas perspectivas próximas como do futuro próximo da criança), o pedagogo pode dirigir real e verdadeiramente a evolução da criança. 
Vigotski (2004) complementa que na discussão do comportamento social em face do desenvolvimento etário das crianças, o conceito de adaptação, princípio orientador das explicações sobre o desenvolvimento na perspectiva psicogenética e de demais teóricos de base funcionalista, é um conceito legitimamente produzido no campo da Biologia moderna e fundamental para explicar o desenvolvimento da vida orgânica na terra. Em Pedagogia corresponderia, segundo esse autor, em reconhecer que o objetivo da educação seria adaptar a criança ao meio que ela terá que viver e agir.

Por outro lado, esta adaptação ao meio se dá de maneira variada e deve ser entendida respeitando dois princípios. O primeiro é de que a adaptação não deve ser considerada senão do ponto de vista social. Isso significa como expõe Vigotski (2004, p.278) que "[...] a relação do homem com o meio deve ter sempre um caráter de atividade e não de simples dependência”. Deste modo, é possível pensarmos numa adaptabilidade representada por uma luta contra elementos do meio, produzida em relações ativas e recíprocas com o mesmo.

Ao lado deste princípio Vigotski (2004) refere-se ao segundo, informando que o comportamento social das crianças deve ser examinado considerando-o refratado em função do desenvolvimento social do organismo. Estes dois princípios são tributários do materialismo histórico dialético a respeito da relação entre a realidade social e as formas de sociabilidade dos homens. Na vida real os indivíduos asseguram sua subsistência adaptando a natureza às suas necessidades no processo do trabalho, atividade que serve de base para todo o desenvolvimento histórico da humanidade.

Tal processo de produção assume na sociedade humana um caráter social amplo fazendo surgir formas complexas de comportamento social das pessoas com as quais as crianças se deparam antes mesmo de chocar-se imediatamente com a natureza (VIGOTSKI, 2004). Como se pode notar esse caráter social que funda as relações produzidas pela atividade humana é extensivo à educação dos homens sendo esta determinada pelo meio social em que eles crescem e desenvolvem-se.

Segundo Carvalho (2002) Vigotski sempre se preocupou com as repercussões de suas reflexões teóricas no campo da educação, orientando-se pelo princípio de que o aprendizado escolar produz algo fundamentalmente novo no desenvolvimento da criança. Vigotski (2004) afirma que a cultura origina formas de conduta, altera as funções psicológicas e constrói novos níveis no sistema de comportamento humano, sendo o sistema escolar responsável por faze com que os indivíduos conceituem e compreendam o mundo não a partir das experiências práticas ou diretamente extraídas 
da realidade, mas porque lida com conceitos teóricos que produzem um processo de abstração e generalização.

De acordo com Vigotski (2004) esses processos de abstração e generalização ocorrem porque não há uma correspondência direta do meio adulto com a criança e porque há uma complexa diversificação de influências do meio, razão pelo qual somos obrigados a rejeitar o princípio espontâneo no processo educacional, contrapondo-lhe uma resistência e administração movida pela organização racional do meio. Nessa elaboração, localizamos a defesa de uma “[...] nova perspectiva para o trabalho escolar”, que é empreender esforços para garantir as aprendizagens das crianças pela intervenção dos processos culturais (VIGOTSKI, 2004, p.10). O conhecimento historicamente acumulado converte-se, enquanto conteúdo das aprendizagens, em aquisições que vão desenvolvendo nas crianças suas características humanas não naturais.

A interpretação de tal preceito psicológico indica os processos de ensino intencionalmente planejados e a valorização dos conhecimentos científicos transformados em conteúdos escolares, como imperativos para um modelo educativo que considera que é pelas aprendizagens proporcionadas pelo trabalho escolar que o desenvolvimento acontece. Isso é coincidente com a perspectiva de um ensino para o conhecimento em oposição ao ensino para o desenvolvimento.

A hegemonia desta última vertente desloca-se na contramão do esforço coletivo de importantes intelectuais brasileiros em suplantar definitivamente os modelos assistencialistas de educação que em seu tempo, produziram práticas educativas que não tinham por princípio e finalidade educacional a promoção das crianças a níveis mais elevados de conhecimento científico e cultural. Ainda que movida por objetivos diversos daqueles presentes nos modelos assistencialistas, a referida vertente, na medida em que atribui um caráter determinante às concepções prévias dos alunos, responsabilizando-os pelo seu percurso pessoal de aprendizagem, enfraquece a perspectiva crítica de contribuição da Psicologia ao campo da Educação produzida no contexto dos anos de 1980 - período de fortalecimento das teorias cognitivistas - pois, revitaliza a desarticulação criticada naquele período, cuja ênfase voltava-se para os processos de aprendizagem em detrimento do ensino.

Parece-nos imprescindível a defesa de uma articulação entre a Psicologia e a Pedagogia sem concessão a nenhum tipo de redução de questões educativas condicionadas por diversos fatores socioculturais a uma dimensão psicológica caracterizada exclusivamente por condicionantes subjetivos. 


\section{Considerações finais}

Um exame nos principais conceitos da perspectiva Histórico-Cultural conduznos à defesa dos processos de educação em seu sentido pleno (isto inclui a educação escolar), como aqueles que consolidam nos indivíduos humanos as funções psicológicas superiores. Vigotskii (2006) antes mesmo de chegar ao conceito formalizado de funções psicológicas superiores desenvolveu conceitos básicos e elementares à luz dos princípios marxistas. Entre estes conceitos queremos destacar a aprendizagem como atividade que possibilita a reconfiguração de um dado externo (fenômenos da realidade de um modo geral) em um dado interno (atividade mental e individual ou processo intra-psíquico).

Esta compreensão além de evidenciar o caráter social do psiquismo humano, evidencia também a indissociabilidade entre atividade externa e interna, consolidando assim o processo de desenvolvimento resultante da continuidade da internalização, processo que ocorre sempre que atividade material prática (externa) se converte em atividade mental (interna). Na base desta compreensão temos o princípio dialético que implica reconhecermos que mesmo na atividade externa há componentes psíquicos que a regulam (ARCE; MARTINS, 2007), entretanto isto não deve sugerir um processo auto-centrado e independente das interações culturais, ao contrário, ele comporta duas dimensões fundamentais para a constituição dos indivíduos: permite-lhes a assimilação dos conteúdos e experiências socialmente acumuladas pela humanidade e ao mesmo tempo converte essas últimas em elementos de suas subjetividades.

Este princípio dialético indica a aprendizagem como o único processo capaz de reconfigurar internamente os dados dos fenômenos externos, ou seja, pelas aprendizagens as funções inatas se reconfiguram, e reestruturam os processos culturalmente formados em substituição aos processos naturais (ARCE; MARTINS, 2007).

Leontiev (1978) ao abordar a relação mais complexa entre o homem e a cultura, indica-nos que assim como uma nova geração começa sua vida num mundo de objetos e fenômenos criados pelas gerações anteriores, o desenvolvimento do pensamento e/ou da aquisição do saber por uma criança forma-se a partir da apropriação dos resultados da atividade cognitiva das gerações precedentes. O autor complementa que "[...] está fora de questão que a experiência individual de um homem, por mais rica que seja, baste 
para produzir a formação de um pensamento lógico ou matemático abstracto e sistemas conceituais correspondentes". (LEONTIEV, 1978, p.266).

Tal defesa empreendida por Leontiev (1978) altera a compreensão inatista de que as aptidões humanas são simplesmente dadas aos homens. Ao contrário, elas produzem-se na relação imposta entre as crianças e os fenômenos culturais circundantes. Esta relação é sempre mediada pelos homens das gerações precedentes sendo que o comprometimento de tal relação implica na descontinuidade do progresso histórico. Isso significa que o movimento da história só é possível com a transmissão às novas gerações das aquisições da cultura humana, processo que se dá invariavelmente a partir da seguinte descrição: nas crianças menores, assim como nas primeiras etapas do desenvolvimento da sociedade humana, o que ocorre é uma simples imitação de atos do meio que se opera “[...] sob o seu controle e com a sua intervenção; depois se complica e especializa-se, tomando formas tais como o ensino e a educação escolar, diferentes formas de formação superior e até formação autodidata”. (LEONTIEV, 1978, p.272).

Vigotski (2004) acrescenta que a natureza do conhecimento científico, defendido por nós como objeto e finalidade de uma educação que se opõe a educar para o desenvolvimento, só pode ser assim concebido desde que verificado e testado pela prática. Entretanto, o homem não descobre as leis da natureza para "[...] resignar-se impotente diante do seu poderio e renunciar a própria vontade." (VIGOTSKI, 2004, p.69). Nem tão pouco para agir irracionalmente frente às leis da natureza ou da sociedade, mas ao subordinar-se racionalmente a elas, ao combiná-las ele as subordina. Isso aumenta o poder dos homens frente às leis naturais e sociais.

Assim deve ser pensada a ampliação do conhecimento cultural e humano produzido na escola engendrada pelas ações pedagógicas. Quanto mais conhecimento as crianças dominam maior o seu poder sobre os processos que determinam suas vidas e suas condições de existência na realidade social. É por essa razão que reconhecermos que a impregnação social da experiência humana como algo que funda os conteúdos das aprendizagens produzidas pelas crianças nos contextos escolares não deve significar reconhecê-las como autômatos ou negar-lhes suas próprias especificidades, ao contrário por esta impregnação elas se convertem em seres sociais que comportam ao mesmo tempo o que há de mais genérico e de mais particular em si.

Evidenciamos assim a defesa de um papel específico para as instituições educativas e que ao mesmo tempo a legitima. Dito de outro modo é através da apropriação dos processos engendrados culturalmente (pela educação) que, no decurso 
da vida as crianças adquirem as propriedades e faculdades verdadeiramente humanas. Segundo Leontiev (1978, p.273) a relação entre o desenvolvimento histórico da humanidade e o progresso da educação é tão estreita que, “[...] se pode sem risco de errar julgar o nível geral de desenvolvimento histórico da sociedade pelo nível de desenvolvimento de seu sistema educativo e inversamente".

Admitir a tese anunciada pelas ideias construtivistas de base psicogenética (WARDE, 2003), de que o desenvolvimento das estruturas intelectuais das crianças se consolida sempre que suas ações se desenvolverem em ambientes adequados a elas, implica em admitirmos que as aprendizagens produzem-se por forças circunstanciais, fruto das ações engendradas pelas crianças entendidas como sujeito racional, individual e natural que dispensa a sistematização de aprendizagens realizada pelos processos educativos formais. É como se admitíssemos que o simples contato das crianças com os fenômenos ou objetos culturais fosse suficiente para garantir-lhes a aquisição dos instrumentos culturais e cognitivos necessários ao seu processo de constituição e humanização.

Em oposição a esta possibilidade, estabelece-se um dos princípios fundamentais do materialismo dialético que nos revela que a relação entre o sujeito que aprende e os objetos que são aprendidos, são relações sociais e históricas, sendo que o desenvolvimento de tais aprendizagens depende das interferências produzidas pelas atividades de outros sujeitos e não somente das ações das crianças em seu sentido natural ou por uma convivência social espontânea.

Nessa perspectiva e considerando a discussão apresentada, podemos afirmar que educar para o desenvolvimento ou para o conhecimento não deve ser uma oposição se considerarmos que o desenvolvimento das crianças é conseqüência de suas interrelações culturais que se ampliam e se formalizam pelas atividades educativas cujo fim deve ser sempre a garantia de acesso às crianças a níveis de desenvolvimento intelectual e social mais elevado.

Isso significa que o diálogo entre a Psicologia e a Pedagogia continua necessário como sempre o foi historicamente, fundamentalmente para refletirmos sobre o fato de que a educação não visa à adaptação no sentido que este conceito assume em teses epistemológicas de cunho evolucionista-cognitivista, entre elas a abordagem psicogenética, de ajuste do indivíduo ao meio, um conjunto de leis funcionais que regulam toda a conduta humana. Esta é uma interpretação esquemática que não considera a complexidade e diversidade das influências do meio sociocultural. 
Pela análise crítica dessa interpretação, somos levados a rejeitar o princípio espontâneo no processo educacional que ela condiciona, opondo-o ao princípio que entende a educação como atividade que promove a humanidade nos indivíduos. Este último soma-se a outros para consolidar uma visão crítica tanto para a Psicologia como para a Pedagogia. Reflexões sobre o homem em processo de educação devem explicitar os elementos constituintes da singularidade de cada indivíduo e sua condição históricosocial, princípio e fundamento de uma Psicologia e Pedagogia sóbrias e suficientemente críticas para aprofundar-se em torno dos fenômenos educativos e psicológicos em suas interfaces.

\title{
BETWEEN THE PSYCHOLOGY AND PEDAGOGY: REFLECTIONS ON CHILD DEVELOPMENT AND KNOWLEDGE SCHOOL IN THE LIGHT OF CULTURAL HISTORICAL THEORY
}

\begin{abstract}
We analyze in this work, the aspects that characterize the relationship with Pedagogy and Psychology of Education, especially the relationship between human development and learning explained by psychogenic theory. We performed a critical analysis of this relationship based on the contributions of cultural-historical theory. We demonstrate that from some precepts, psychogenic theory establishes a model of education that takes the development of cognitive processes as basic content for educational, considering that successful transmission of knowledge to children depends primarily on the existence of schemes assimilation inherent in the activity of the subject. However, guided by Cultural- Historical theory we reaffirm an understanding of child as an individual who needs learn and grow in a world of objects, people and places of knowledge holders. So it should be considered the expansion of cultural knowledge and human produced engendered by the school pedagogical actions. The more knowledge children master greatest power over the processes that determine their lives and their conditions of existence in the social reality. That is, through the appropriation of culturally engendered processes (for education), in the course of life children acquire the properties and truly human faculties.
\end{abstract}

KEY WORDS: Psychology of education. Psychogenetic. Cultural-Historical Theory. Early childhood education.

\section{REFERÊNCIAS}

ARCE, A.; MARTINS, L. M. Quem tem medo de ensinar na educação infantil? Em defesa do ato de ensinar. Campinas: Alínea, 2007.

BRASIL. Constituição (1988). Constituição da República Federativa do Brasil: promulgada em 5 de outubro de 1988. Organização do texto por Juarez de Oliveira. 4.ed. São Paulo: Saraiva, 1990. 
Ministério da Educação e do Desporto. Secretaria de Educação Fundamental.

Referencial curricular nacional para a educação infantil. Brasília: MEC/SEF, 1998.

CARVALHO, D. C. A psicologia frente a educação e o trabalho docente. Psicologia em Estudo, Maringá, v.1, n.7, p.1-13, 2002.

CHAIKLIN, S. A zona de desenvolvimento próximo na análise de Vigotski sobre aprendizagem e ensino. Tradução de J. C. Pasqualini. Psicologia em Estudo, Maringá, v.16, n.4, p.659-675, out./dez. 2011.

COLL, C.; MARTÌ, E. Aprendizagem e desenvolvimento: a concepção genéticocognitiva da aprendizagem. In: COLL, C.; PALACIOS, J.; MARCHESI, A. (Org.). Desenvolvimento psicológico e educação: psicologia da educação. Tradução de A. M. Alves. Porto Alegre: ARTMED, 1996. p.105-121.

DUARTE, N. Vigotski e o aprender a aprender: críticas às apropriações neoliberais e pós-modernas da teoria vigotskiana. 3.ed. Campinas: Autores Associados, 2004.

ELKONIN, D. B. Desarrollo psíquico de los niños. In: SMIRNOV, A. A. (Org.). Psicologia. Tradução de F. Villa Landa. 3.ed. México: Editorial Grijalbo, 1969. p.493560.

LEONTIEV, A. N. O desenvolvimento do psiquismo. Lisboa: Livros Horizonte, 1978.

LOMBARDI, J. C. Reflexões sobre educação e ensino na obra de Marx e Engels.

2010. 377 f. Tese (Livre - Docência) - Faculdade de Educação, Departamento de

Filosofia e História da Educação, Universidade Estadual de Campinas, Campinas, 2010.

PIAGET, J. Aprendizagem e conhecimento. Rio de Janeiro: Freitas Bastos, 1974.

Psicologia e pedagogia. Tradução de D. A. Lindoso e R. M. R. Silva. 9.ed. Rio de Janeiro: Forense Universitária, 2003.

ROSEMBERG, F. Organizações multilaterais, estado e políticas de educação infantil. Cadernos de Pesquisa, São Paulo, n.11, mar. 2002. Disponível em: <http://www.scielo.br/pdf/cp/n115/a02n115.pdf>. Acesso em: 10 mar. 2006.

VIGOTSKI, L. S. Psicologia pedagógica. Tradução de P. Bezerra. 2.ed. São Paulo: Martins Fontes, 2004.

Aprendizagem e desenvolvimento intelectual na idade escolar. In: VIGOTSKII, L. S.; LURIA, A. R.; LEONTIEV, A. N. Linguagem, desenvolvimento e aprendizagem. Tradução de M. P. Villalobos. 10.ed. São Paulo: Ícone, 2006. p.103118.

WARDE, M. J. Para uma história disciplinar: psicologia, criança e pedagogia. In: FREITAS, M. C. (Org.). História social da infância no Brasil. 5.ed. São Paulo: Cortez, 2003. p.311-332. 